\title{
Michel Pêcheux. Las verdades evidentes: lingüística, semán- tica, filosofía. Ciudad Autónoma de Buenos Aires. Ediciones del CCC Centro Cultural de la Cooperación Floreal Gorini. 2016. 246 pp.
}

Karina Savio ${ }^{1}$

El presente libro es la primera traducción al español de una de las obras que más ha influido y repercutido en ese dominio del saber que se suele reunir bajo el nombre de "Escuela francesa de Análisis del Discurso", cuyas fronteras no siempre se han podido trazar con precisión y nitidez. Escrita en francés en 1975 por el filósofo del lenguaje Michel Pêcheux (1938-1983), discípulo de Louis Althusser, bajo el título de Les Vérités de La Palice. Linguistique, sémantique, philosophie por la editorial Maspero, es ahora publicada en la Argentina en la colección Historia del Presente de las Ediciones del CCC (editorial del Centro Cultural de la Cooperación "Floreal Gorini”), con la traducción de un equipo interdisciplinario compuesto por Mara Glozman, Pedro Karczmarczyk, Guadalupe Marando y Margarita Martínez.

La producción de Michel Pêcheux - que puede ser fechada entre fines de la década de 1960 y comienzos de los años '80, hasta su muerte en 1983- trastocó el modo de comprender, explicar y abordar analíticamente los procesos y las materialidades discursivas. Es, en este sentido, el fundador de una línea de investigación que enlaza e integra -en un complejo entramado- el marxismo althusseriano, la lingüística, la filosofía del lenguaje y el psicoanálisis lacaniano, junto a otras referencias teóricas. Advertido de las contradicciones de distintas corrientes lingüísticas y filosóficas, elabora y promueve una teoría materialista del lenguaje que se interesa fundamentalmente por el discurso, entendido en tanto efecto de sentidos, en la que se entrecruzan términos centrales como los de sujeto, ideología e inconsciente, entre otros. Bajo este horizonte, analiza y estudia los diversos modos en los que el funcionamiento discursivo interviene en los diferentes procesos de significación determinados históricamente; posición que, sostenida, entre otros elementos, por el sujeto dividido por el significante de Jacques Lacan, horada la visión dominante dentro de los enfoques lingüísticos y filosóficos que pregonan la existencia de un sentido evidente y de un sujeto (hablante) dueño de su decir. Entre los enormes aportes que Pêcheux ha hecho en este sentido, se puede mencionar la (re)formulación de una serie de conceptos que, desde entonces, han sido nodales para la producción de conocimiento. Nos referimos a nociones como las de condiciones de producción, formación discursiva (formulada inicialmente en 1969 por Michel Foucault, en el marco de su Arqueología del saber), discurso transverso, interdiscurso, memoria discursiva, entre otras. Gran parte de estos conceptos ha sido y es retomada de manera recurrente en el campo de los estudios sobre el discurso.

Dentro de la obra pecheuxtiana, Las verdades evidentes se inscribe -y así lo ha señalado el propio autor algunos años después- en una segunda etapa o período del análisis del discurso en el que se problematizan, a los fines de asentar las bases de una teoría

1 Doutora em Letras e Professora da Universidade de Buenos Aires - UBA. Pesquisadora do CONICET. 
del discurso, las cuestiones del sentido, el sujeto, la producción científica y la práctica política, articulados a partir de pensar su interrelación con los procesos ideológicos. Las nociones de interdiscurso, preconstruido y formaciones discursivas, que permiten concebir un discurso anclado en sus condiciones de producción, encuentran en este volumen un lugar para su cimentación y estructuración teórica. Podría considerarse que el texto transvasa, por otra parte, los límites de los estudios del discurso tal como se los entiende generalmente en la actualidad. Ya desde el subtítulo-Lingüística, semántica, filosofía-el texto se orienta al trabajo sobre problemáticas que atraviesan distintos "campos" antes que a una inscripción disciplinar dada de antemano.

El libro publicado en Buenos Aires es fiel a la estructura de la publicación francesa de 1975: cuenta con una introducción, una conclusión y dos anexos (“¿Una teoría científica de la propaganda?" y "Algunas repercusiones posibles en las investigaciones lingüísticas”), y está organizado a partir de cuatro capítulos. El periplo discursivo nace, en el primer capítulo, titulado "Lingüística, lógica y filosofía del lenguaje", a raíz del cuestionamiento de ciertas evidencias fundadoras de la semántica. En efecto, Pêcheux busca demostrar en estas primeras páginas cómo por debajo de las problemáticas lingüísticas subyacen cuestiones filosóficas. A través de una ardua revisión histórica, por un lado, evidencia que desde la filosofía aristotélica hasta los estudios de la semántica vigentes en 1975 existe una circularidad ideológica que retoma la oposición entre lógica y retórica y que compromete la reflexión lingüística como una especie de "filosofía espontánea", y, por el otro, revela cómo el idealismo filosófico ha intentado unificar ambos espacios. Esta primera parte concluye a partir de la enunciación de las tres tesis fundamentales del materialismo, de las que se desprende la dependencia del sujeto respecto del mundo exterior.

Son los capítulos dos y tres, "De la filosofía del lenguaje a la teoría del discurso" y "Discurso e ideología(s)", respectivamente, los que condensan, por su parte, la matriz conceptual en la que se asienta la teoría materialista del lenguaje, que se interroga por las condiciones de reproducción/transformación de las relaciones de producción en su vinculación con el discurso. Polemizando con la noción saussureana de habla, que la concibe como el uso individual de la lengua, el autor muestra el modo en que los procesos discursivos están insertos en una relación ideológica de clase a través de la que el sujeto se constituye. Incorpora, por un lado, la definición althusseriana que afirma que es la ideología la que interpela a los individuos en sujetos y, por el otro, distingue formación ideológica, ideología dominante e Ideología. A partir de allí sostiene que la constitución del sentido no puede separarse y analizarse aisladamente de la constitución del sujeto. Las nociones de preconstruido -concepto introducido por P. Henri-, formación discursiva e interdiscurso confrontan aquí con el imaginario lingüístico en el que se proclama la transparencia en el lenguaje y que, por ende, enmascara el carácter material del sentido de las palabras y de los enunciados.

El autor plantea, entonces, que las palabras, las expresiones, las proposiciones reciben su sentido de la formación discursiva en la que son producidas, dado que ella establece, en una formación ideológica dada, lo que puede y debe ser dicho. En palabras de Pêcheux: “el sentido de una palabra, de una expresión, de una proposición, etc., no existe 'en sí mismo' (es decir, en su relación transparente con la literalidad del significante), sino que está determinado por las posiciones ideológicas puestas en juego en el proceso social-histórico en el que las palabras, expresiones y proposiciones son producidas (es decir, reproducidas)". (2016: 142). El sujeto del discurso queda, a su vez, sujetado a esta formación bajo el olvido de los trazos de aquello que lo designa, lo que vislumbra la aparición 
de la forma-sujeto. Lo preconstruido, es decir, las construcciones anteriores, exteriores al enunciado, lo que no está "construido" en y por el enunciado, se presenta en este andamiaje desde lo ya dado y su efecto consiste, por ello, en un desfasaje.

En el cuarto capítulo, "Los procesos discursivos en las ciencias y en la práctica política", finalmente, arriba a la pregunta por la producción científica de conocimiento y por la práctica política revolucionaria proletaria. Se discute en este último tramo con la "evidencia" según la cual el hombre produce conocimientos científicos, dado que las condiciones de producción de estos conocimientos están inscriptas en las condiciones de reproducción/transformación de las relaciones de producción. La ruptura epistemológica es pensada, en este escenario, como una puesta en cuestión de la forma-sujeto y de la evidencia del sentido que esta incluye. La práctica política proletaria supone, en esta misma línea, un trabajo de transformación-desplazamiento de la forma sujeto que, sin implicar una posible desubjetivación, asuma la forma de una des-identificación.

En función de los temas que se tratan, Pêcheux ofrece el contenido de este libro a lingüistas y filósofos. Por tal razón, en esta edición se ha decidido incorporar dos prólogos esenciales e ineludibles -escritos por Mara Glozman ("Lingüística, materialismo, (inter) discurso: elementos para una lectura de Las verdades evidentes") y Pedro Karczmarczyk ("La problemática teórica althuseriana y Las verdades evidentes")- que proponen, tomando en cuenta estas dos miradas, distintas entradas al texto. Estas dos lecturas no solo contribuyen a orientar y facilitar el tránsito por las ideas pecheuxtianas, sino que las insertan en otras tramas discursivas que invitan al lector a asumir nuevas preguntas respecto a los debates que este volumen abre.

A pesar de haber sido escrito en 1975, las problemáticas que se abordan en Las verdades evidentes no han perdido hoy ni interés ni vigencia. En este sentido, la actualidad de los planteos que allí se iluminan y la relevancia de los términos que se desarrollan interpelan al lector para que se sumerja en un recorrido atento y minucioso, a través del cual podrá armar, desarmar y rearmar un fragmento clave del sinuoso pensamiento de Pêcheux.

Recebido em: 15/05/2017 Aceito em: 23/05/2017 